\title{
ESTABELECIMENTO E DESENVOLVIMENTO DE DALBERGIA MISCOLOBIUM BENTH. EM DUAS FITOFISIONOMIAS TÍPICAS DOS CERRADOS DO BRASIL CENTRAL
}

\author{
Vívian S. Braz \\ Mieko F. Kanegae \\ Augusto C. Franco ${ }^{1,2}$
}

Recebido em 13/07/1999. Aceito em 06/12/1999

RESUMO - (Estabelecimento e desenvolvimento de Dalbergia miscolobium Benth. em duas fitofisionomias típicas dos cerrados do Brasil Central). As formações savânicas do Brasil Central caracterizam-se por uma camada rasteira contínua, em que predominam gramíneas, entrecortada por uma camada de arbustos e árvores de densidade variável. Dalbergia miscolobium Benth. é uma leguminosa arbórea típica dos cerrados do Planalto Central. Este estudo examinou os efeitos da seca, disponibilidade de luz, herbivoria e fogo no estabelecimento e crescimento dessa espécie no campo sujo (estrato herbáceo contínuo com árvores e arbustos esparsos) e no cerrado sensu stricto, onde a vegetação arbustivoarbórea é mais densa. Mudas foram transplantadas nas duas fitofisionomias, sendo acompanhadas mensalmente as variaçães na altura, produção de folhas e percentagem da área foliar removida por herbivoria, ao longo de cinco anos (1993-1998). A mortalidade ocorreu principalmente durante a época chuvosa. A seca sazonal não foi um importante fator de mortalidade. Número maior de mudas sobreviveu no campo sujo. Estas mudas não foram mortas por uma queimada ao final da seca de 1994, enquanto várias morreram no cerrado. O crescimento da parte aérea foi lento, em torno de $2,2 \mathrm{~cm} /$ ano no campo sujo e $3,1 \mathrm{~cm} /$ ano no cerrado, ocorrido principalmente na estação chuvosa. A maioria das mudas apresentou lesões necróticas de cor preta nas folhas, causada pelo ataque do fungo Phoma sp. A queda das folhas ocorreu durante a estação seca e o número máximo de folhas foi alcançado do meio para o final da época chuvosa, sempre seguido por um pico na herbivoria. Dados de disponibilidade de luz sugerem que plantas com folhas horizontais a $5 \mathrm{~cm}$ do solo, atingiriam em média apenas $32 \%$ da capacidade máxima de assimilação de $\mathrm{CO}_{2}$, devido ao sombreamento. Entretanto, aumento da altura da planta de 5 para $50 \mathrm{~cm}$, onde não há mais sombreamento do estrato herbáceo, dobraria os valores estimados de assimilação de $\mathrm{CO}_{2}$. Assim sendo, o desenvolvimento desta espécie seria limitado pela disponibilidade de água e herbivoria na seca e pelo sombreamento e ataque de patógenos na estação chuvosa.

Palavras-chave - crescimento, estresse hídrico, fenologia, herbivoria, sombreamento, sobrevivência

ABSTRACT - (Establishment and development of Dalbergia miscolobium Benth in two typical savanna physiognomies of Central Brazil). The savannas of Central Brazil are characterized by a continuous,

Departamento de Botânica, Universidade de Brasília, C. Postal 4457, CEP 70919-970, Brasília, DF, Brasil. e-mail: acfranco@unb.br

2 Autor para correspondência. Departamento de Botânica, Universidade de Brasília, C. Postal 04457, CEP 70919-970, Brasília, DF 
predominantly grassy, ground layer and an open layer of trees and shrubs of a variable density. In this study we examined the effects of drought, habitat type, the canopy light condition, herbivory and fire in the establishment and growth of Dalbergia miscolobium Benth., a legume tree typical of the savannas of Central Brazil. Saplings were transplanted into the grass matrix of a grassland with scattered trees and shrubs ("campo sujo"), and into the semi-closed canopy of shrubs and trees that characterized the "cerrado" physiognomy. Sapling survival, shoot growth, leaf production and leaf herbivory were followed monthly over a five-year period (1993-1998). Mortality occurred predominantly during wet periods, and seasonal drought was not an important mortality factor. Sapling survival was greater in the "campo sujo" and they even survived a fire at the end of the dry season of 1994, while several saplings at the cerrado site were killed. Shoot growth was low, about $2.2 \mathrm{~cm} /$ year in the "campo sujo", and $3.1 \mathrm{~cm} /$ year in the "cerrado", mostly in the wet season. Leaves were shed during the dry season, and the peak in number of leaves in mid to late wet season was followed by a peak in leaf area loss by herbivory. Necrotic black spots, caused by the fungus Phoma sp. were observed in the leaves of most plants. Canopy shading could limit $\mathrm{CO}_{2}$ assimilation $\left(\mathrm{AcO}_{2}\right)$ in the initial phases of plant development. Light measurements suggested that $5 \mathrm{~cm}$ tall saplings with horizontal leaves would receive enough light to reach, on an average only $32 \%$ of maximum $\mathrm{A}_{\mathrm{CO} 2}$ during the daylight period. Since the height of the grass layer was mostly less than $50 \mathrm{~cm}$, an increase in plant height from 5 to $50 \mathrm{~cm}$ would result in a twofold increase of $\mathrm{AcO}_{2}$ averaged over the daylight period. Thus, the development of D. miscolobium was restricted by water stress and herbivory during the dry season, and by shading and pathogen attack during the wet season.

Key words - growth, water stress, phenology, herbivory, shading, survivorship

\section{Introdução}

O cerrado é uma vegetação típica do Brasil Central, apresentando, em suas formas savânicas, fisionomias que possuem um estrato herbáceo contínuo, com árvores e arbustos esparsos (campo sujo) e áreas onde a vegetação arbustivo-arbórea é mais densa (cerrado sensu stricto).

O clima é tropical, caracterizado pela alternância entre uma estação chuvosa, no verão, e outra seca, no inverno. Os solos geralmente apresentam acidez elevada e são muito deficientes em bases trocáveis ( $\mathrm{K}, \mathrm{Ca}$ e $\mathrm{Mg}$ ), resultando em altas taxas de saturação por alumínio (Batmanian \& Haridasan 1985).

Modelos para explicar este tipo de ecossistema consideram as variações sazonais na disponibilidade de água como o recurso limitante mais importante e pressupõem que os elementos lenhosos são capazes de invadir a matriz herbácea (Medina \& Silva 1990). Existem poucos estudos que investigaram os padrões de estabelecimento de espécies lenhosas nos cerrados. Laboriau et al. (1963) encontraram plântulas de espécies lenhosas nativas em condições naturais e Handro (1969) relatou que mudas de Andira humilis Mart. ex Benth., com dois meses de idade, transplantadas no cerrado durante a estação chuvosa, eram capazes de sobreviver à estação seca subsequente. Oliveira \& Silva (1993), em trabalho com duas espécies de Kielmeyera no cerrado, mostraram que estas germinavam prontamente no campo e as plântulas resultantes apresentavam alta taxa de sobrevivência, apesar da ação do fogo e de seca intensa que ocorreu no primeiro ano. Hoffmann (1996) relatou que várias espécies lenhosas do cerrado apresentavam maior sobrevivência quando germinavam debaixo da copa das árvores do que na matriz herbácea. Nardoto et al. (1998) concluíram que, em ambientes de campo sujo, a disponibilidade de água restringe a produtividade de $K$. coriacea (Spr.) Mart., espécie caducifólia típica do cerrado, na época seca, enquanto o sombreamento pelo estrato herbáceo limita sua produtividade na época chuvosa. Desta maneira, à medida que o dossel arbustivo-arbóreo torna-se mais fechado, a 
disponibilidade de luz pode se tornar fator ainda mais crítico para o estabelecimento e crescimento de espécies arbóreas do cerrado.

Além dos fatores abióticos, as interações biológicas podem afetar marcadamente a produtividade e a sobrevivência de determinada espécie, principalmente nas fases iniciais de desenvolvimento. Estudos sobre herbivoria em plantas lenhosas do cerrado são escassos e limitaram-se a examinar os efeitos da herbivoria em indivíduos adultos. Os poucos dados disponíveis sugerem que a pressão de herbivoria é maior em folhas novas (Fowler \& Duarte 1991). Para indivíduos adultos de Roupala montana Aubl., espécie de folhas perenes, típica dos cerrados do planalto central, a herbivoria causou uma redução de cerca de $16 \%$ na área foliar disponível (Franco 1998). Os efeitos de herbivoria são, provavelmente, mais intensos em indivíduos jovens de plantas do cerrado. Desta maneira, estudos que integrem medições de crescimento e dos efeitos dos fatores abióticos e bióticos que limitam o crescimento e o estabelecimento de plantas lenhosas, são essenciais para a compreensão dos processos de colonização e regeneração dos ecossistemas savânicos característicos do Brasil Central.

Este estudo teve como objetivo examinar os efeitos da estação seca, herbivoria e disponibilidade de luz na sobrevivência, crescimento e produtividade de indivíduos jovens de Dalbergia miscolobium (Fabaceae) em uma área de campo sujo e uma de cerrado sensu stricto, durante o período de cinco anos (1993 a 1998). Além disso, ocorreu uma queimada acidental em outubro/1993, o que permitiu observar o efeito do fogo na sobrevivência e na produtividade dessa espécie. D. miscolobium é árvore típica dos cerrados do Planalto Central, popularmente conhecida como careiúna ou jacarandá-do-cerrado. Normalmente floresce ao final da estação chuvosa, passando grande parte da estação seca na fase de formação e amadurecimento dos frutos, que são dispersos pelo vento ao final desta estação. A germinação ocorre ao início da esta- ção chuvosa. Franco et al. (1996) mostraram que sementes de $D$. miscolobium são capazes de germinar no campo sujo e no cerrado.

\section{Material e métodos}

O presente estudo foi realizado na Estação Experimental da Fundação Universidade de Brasília (Fazenda Água Limpa), a cerca de $20 \mathrm{~km}$ ao sul da cidade de Brasília ( $15^{\circ} 57^{\prime} \mathrm{S}$ e $47^{\circ} 55^{\prime} \mathrm{O}$ ), altitude de cerca de $1060 \mathrm{~m}$. De acordo com os dados da estação metereológica da Reserva Ecológica do IBGE (155' S; $47^{\circ}$ $57^{\prime}$ O), a precipitação média anual fica ao redor de $1500 \mathrm{~mm}$, com uma estação seca bem definida de maio a setembro.

O experimento teve início em maio/1993, quando mudas de $D$. miscolobium foram transplantadas para uma área de campo sujo e uma área de cerrado sensu stricto, no total de 18 indivíduos em cada ambiente. Como as mudas foram transplantadas ao final da estação chuvosa, a maioria não sobreviveu. Desta maneira, o procedimento foi repetido com mudas de aproximadamente nove meses de idade, também no total de 18 em cada ambiente, em dezembro/ 1993. A maior parte das análises foi feita com os indivíduos do segundo experimento. As mudas no campo sujo foram transplantadas no meio da matriz herbácea, enquanto as mudas no cerrado foram transplantadas próximas a arbustos e árvores, na zona de influência da copa.

Todos os meses mediu-se o comprimento da parte aérea de cada planta, o diâmetro basal, o número de folhas presentes e a percentagem de área foliar destas folhas que foram removidas, considerado como sendo por herbivoria. O comprimento da parte aérea inclui o comprimento de todos os ramos, além do caule, nos casos em que ocorreu bifurcação. A planta era considerada morta se perdia todas as folhas e não rebrotava na estação chuvosa subseqüente. Considerou-se que a morte da planta ocorreu na primeira data em que esta não apresentava folhas.

A intensidade de luz foi determinada com 
fotodiodos instalados em haste metálica a 5, $10,15,20$ e $50 \mathrm{~cm}$ de altura do chão, acopladas a milivoltímetro. Os fotodiodos foram previamente calibrados em densidade de fluxo de fótons na faixa de radiação fotossinteticamente ativa (DFF; $\lambda=400-700 \mathrm{~nm}$ ) contra um sensor de quanta, da LICOR, U.S.A, modelo 190-S. Medições do curso diário da DFF foram obtidas em intervalos de meia hora, em dia típico do final da estação chuvosa (26/maio/1996) e do início da estação chuvosa (27/outubro/1996), na área experimental de campo sujo e de cerrado sensu stricto, sem modificar a vegetação local, no total de seis réplicas em cada ambiente. Os fotodiodos ficaram orientados paralelos à superfície do solo e mediram a DFF incidente numa superfície horizontal em cada uma das cinco alturas. Os fotodiodos a $50 \mathrm{~cm}$ de altura estavam acima do dossel graminoso. Em 26/maio/1998 os dados foram coletados entre $8 \mathrm{~h}$ e $45 \mathrm{~min}$ e $18 \mathrm{~h}$ e $15 \mathrm{~min}$. Em $27 /$ outubro entre $7 \mathrm{~h}$ e $55 \mathrm{~min}$ e $17 \mathrm{~h}$ e $25 \mathrm{~min}$.

A assimilação líquida instantânea de $\mathrm{CO}_{2}$ $\left(\mathrm{A}_{\mathrm{CO} 2}\right)$ em função da DFF foi estimada a partir da equação $\mathrm{A}_{\mathrm{CO} 2}=-0,75+6.00 *\left[1-\mathrm{e}^{(-\mathrm{DFF} / 314,89)}\right] \mathrm{ob}-$ tida por Sassaki et al. (1997), para folhas de $D$. miscolobium em casa de vegetação.

\section{Resultados}

Segundo os dados da Reserva Ecológica do IBGE, a precipitação média anual de 1994 a 1998 ficou em $1.475 \mathrm{~mm}$. A Fig. 1 apresenta os dados de variação mensal das chuvas e temperatura para esse período. O período seco (menos de $40 \mathrm{~mm}$ ) estendeu-se de maio à setembro, com exceção dos anos de 1996, em que ocorreu o total de $48 \mathrm{~mm}$ entre os dias 12 e 17/agosto, e 1997 , em que choveu mais de $100 \mathrm{~mm}$ em maio e $70 \mathrm{~mm}$ entre os dias 11 e 26/setembro. Os meses mais quentes foram setembro e outubro, e os valores mínimos de temperatura ocorreram entre junho e julho em todos os anos. A temperatura média anual entre os anos de 1994 e 1998 ficou em torno de $22,7^{\circ} \mathrm{C}$.

Maior número de plantas sobreviveu no campo sujo nos dois experimentos. Das $18 \mathrm{mu}-$ das transplantadas em cada fitofisionomia em maio/1993, cinco permaneciam vivas no campo sujo, e três no cerrado, em dezembro/1998. Das 18 transplantadas em cada ambiente em dezembro/1993, dez estavam vivas no campo. sujo em dezembro/1998, enquanto no cerrado, apenas seis sobreviveram (Fig. 2). Em ambos os ambientes, a maior parte da mortalidade ocorreu durante a estação chuvosa. No campo sujo, a queimada acidental de 1994 não afetou a sobrevivência, enquanto as mudas transplantadas

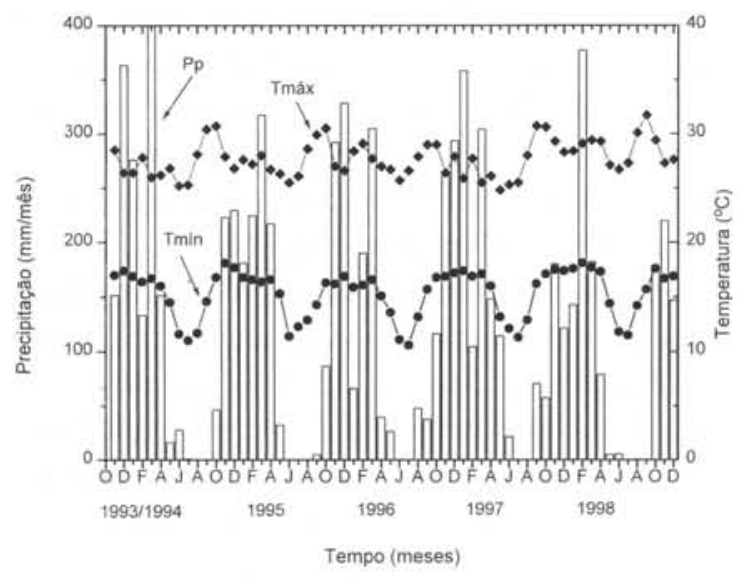

Figura 1. Total mensal de precipitação (Pp), média mensal das temperaturas máximas (Tmáx) e mínimas (Tmín), conforme os dados da Reserva Ecológica do IBGE, DF.

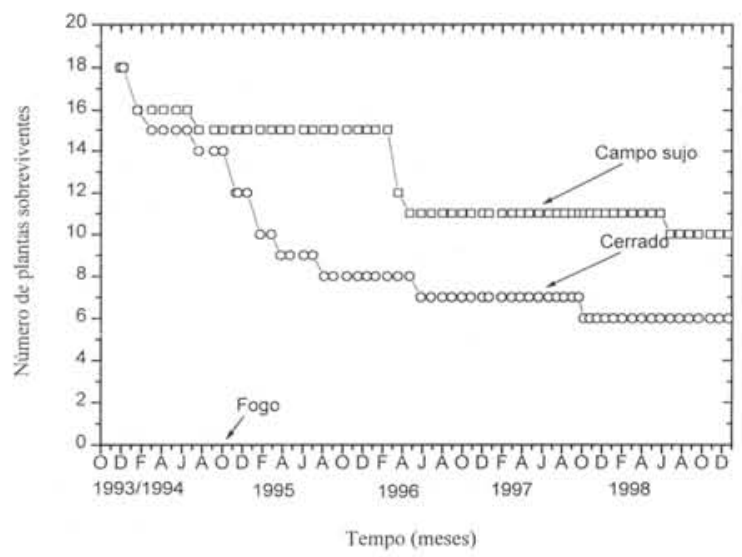

Figura 2. Número de indivíduos sobreviventes de $D$. miscolobium transplantados para uma área de campo sujo e uma área de cerrado da Fazenda Água Limpa, DF. As mudas foram transplantadas em dezembro/1993. "Fogo" corresponde à queima acidental das áreas experimentais ocorrida em 3/outubro/1994. 
no cerrado sofreram mortalidade acentuada após a passagem do fogo.

As plantas transplantadas em maio/1993 que sobreviveram, desenvolveram-se melhor no campo sujo (Tab. 1). Estas plantas tiveram crescimento significativamente maior $(\mathrm{t}=2,28$; $\mathrm{GL}=6 ; \mathrm{P}=0,06$ ), maior número de folhas na copa (teste de Kruskal-Wallis; $\mathrm{P}=0,02$ ) e maior diâmetro $(\mathrm{t}=2,62 ; \mathrm{GL}=6 ; \mathrm{P}=0,04)$. As plantas transplantadas em dezembro/1993 não apresentaram diferença significativa de crescimento da parte aérea $(\mathrm{t}=0,15 ; \mathrm{GL}=14 ; \mathrm{P}=0,88)$ e número de folhas da copa (teste de Kruskal-Wallis; $\mathrm{P}=0,87$ ) entre as fitofisionomias (Tab. 2). Entretanto, o diâmetro das mudas do campo sujo foi signifi-

Tabela 1. Valores (média \pm erro padrão) de comprimento total da parte aérea, diâmetro basal e número de folhas presentes nas mudas de $D$. miscolobium do primeiro experimento, que sobreviveram ao longo de todo o período de estudo (maio/1993 a dezembro/1998)

\begin{tabular}{lcc}
\hline & $\begin{array}{c}\text { Campo sujo } \\
(\mathrm{n}=5 \text { plantas })\end{array}$ & $\begin{array}{c}\text { Cerrado } \\
(\mathrm{n}=3 \text { plantas })\end{array}$ \\
\hline Comprimento $(\mathrm{cm})$ & $20,3 \pm 1,7$ & $13,3 \pm 2,9$ \\
Diâmetro $(\mathrm{mm})$ & $2,2 \pm 0,2$ & $1,4 \pm 0,3$ \\
Número de folhas & $5,4 \pm 0,7$ & $3,7 \pm 0,6$ \\
\hline
\end{tabular}

Tabela 2. Valores (média \pm erro padrão) de comprimento total da parte aérea, diâmetro basal e número de folhas presentes nas mudas de $D$. miscolobium do segundo experimento, que sobreviveram ao longo de todo o período de estudo (dezembro/1993 a dezembro/1998)

\begin{tabular}{lcc}
\hline & $\begin{array}{c}\text { Campo sujo } \\
(\mathrm{n}=10 \text { plantas })\end{array}$ & $\begin{array}{c}\text { Cerrado } \\
(\mathrm{n}=6 \text { plantas })\end{array}$ \\
\hline Comprimento $(\mathrm{cm})$ & $17,4 \pm 1,3$ & $17,1 \pm 2,2$ \\
Diâmetro $(\mathrm{mm})$ & $2,3 \pm 0,1$ & $1,9 \pm 0,1$ \\
Número de folhas & $3,8 \pm 0,5$ & $3,7 \pm 0,6$ \\
\hline
\end{tabular}

cativamente maior $(\mathrm{t}=2,47 ; \mathrm{GL}=14 ; \mathrm{P}=0,03)$ do que as do cerrado.

As Fig. 3 e 4 mostram o padrão sazonal de crescimento do caule, número de folhas na copa e percentagem da área destas folhas que foi removida por herbivoria, para as mudas transplantadas em dezembro/1993. O incremento da par- te aérea foi lento, apresentando taxa de crescimento (entre dezembro/1994 e dezembro/1998) em torno de $2,2 \mathrm{~cm} /$ ano no campo sujo, e $3,1 \mathrm{~cm} /$ ano no cerrado, ocorrido principalmente na época das chuvas (Fig. 3 ). Na época seca o crescimento foi nulo ou pouco expressivo, acontecendo inclusive redução do comprimento da parte aérea em alguns casos.

O fogo ocorrido em outubro/1994 causou perda total da parte aérea. As plantas sobreviventes rebrotaram a partir da base, ocorrendo crescimento acentuado da parte aérea nos primeiros meses após o fogo (Fig. 3). Estas plantas cresceram em média $6,9 \mathrm{~cm}$ no campo sujo,

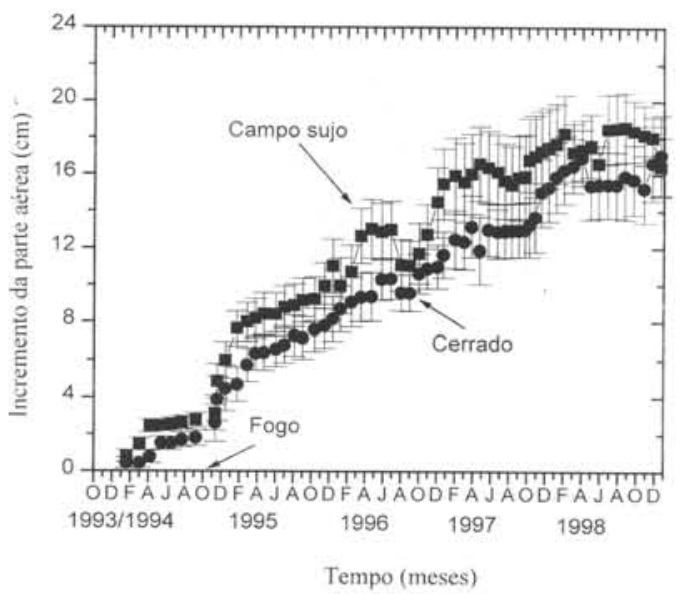

Figura 3. Incremento acumulado da parte aérea das mudas de D. miscolobium que foram transplantadas em dezembro/1993, para uma área de campo sujo e uma área de cerrado da Fazenda Água Limpa, DF. "Fogo" corresponde à queima acidental das áreas experimentais ocorrida em 3/outubro/1994. Dados expressos em termos de média \pm erro padrão.

e $5,5 \mathrm{~cm}$ no cerrado, entre outubro/1994 e fevereiro/1995.

Em ambas as fitofisionomias, as plantas apresentaram sazonalidade bem marcada na produção e perda de folhas (Fig. 4A). Ao longo dos cinco anos, as folhas foram produzidas no início das chuvas, atingindo o máximo de 2 a 4 folhas por indivíduo, entre os meses de fevereiro a abril (Fig. 4A). A queimada acidental levou a um pico de produção de folhas ( 5 a 7 folhas por indivíduo; Fig. 4A). Em todos os anos, as 


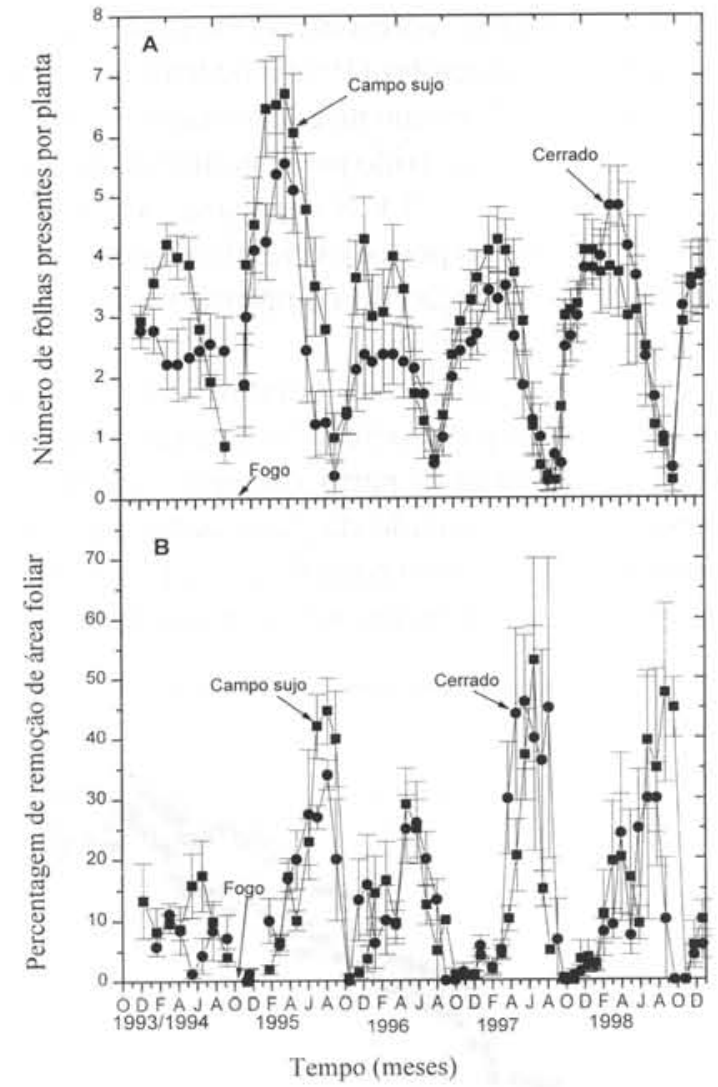

Figura 4. (A) Número médio de folhas e (B) percentagem de remoção da área do limbo das folhas em mudas de $D$. miscolobium que foram transplantadas em dezembro/1993, para o campo sujo e o cerrado da Fazenda Água Limpa, DF. Dados expressos em termos de média \pm erro padrão, para o período de dezembro/1993 a dezembro/1998. "Fogo" corresponde à queima acidental das áreas experimentais ocorrida em 3/outubro1994.

folhas foram perdidas ao longo da estação seca e a maioria dos indivíduos estava sem folhas ao final dessa estação. A maioria dos indivíduos apresentou lesões necróticas de cor preta nas folhas, causada pelo ataque do fungo Phoma sp. Observou-se, ao longo dos anos, que, logo após um pico de produção de folhas ocorria um pico na herbivoria (Fig. 4A, B).

A Fig. 5 mostra os valores integrados de DFF incidentes numa superfície horizontal, a diferentes alturas do solo, em dia típico do início e do final da estação chuvosa, nas duas fitofisionomias. De maneira geral, os valores encontrados no campo sujo foram maiores que os encontrados no cerrado. Esta diferença se tornaria mais marcante à proporção que a planta crescesse. Por exemplo, uma planta de $5 \mathrm{~cm}$, com folhas horizontais, receberia aproximadamente a mesma quantidade de luz no campo sujo e no cerrado. Em contraste, uma planta de $50 \mathrm{~cm}$ de altura no cerrado, receberia entre 58 e $74 \%$ da DFF que atingiria uma planta de mesma altura no campo sujo. Em ambas as fitofisionomias, aumento na altura levou ao aumento na DFF incidente. Duas a três vezes mais DFF incidiu sobre uma superfície horizontal a $50 \mathrm{~cm}$ de altura do que a $5 \mathrm{~cm}$ de altura (Fig. 5).

$\mathrm{O}$ sombreamento limitaria potencialmente as taxas de assimilação de $\mathrm{CO}_{2}$ nos dois ambientes (Fig. 6). Indivíduos de D. miscolobium, em condições ótimas de luminosidade, teriam valor máximo de assimilação de $\mathrm{CO}_{2}\left(\mathrm{~A}^{\max }\right)$ de $5,25 \mu \mathrm{mol} \cdot \mathrm{m}^{-2} \cdot \mathrm{s}^{-1}$ (Sassaki et al. 1997). Desta maneira, plântulas com folhas a $5 \mathrm{~cm}$ de altura atingiriam, em média, apenas $32 \%$ de $\mathrm{A}^{\max }$ nas duas áreas, enquanto que folhas a $50 \mathrm{~cm}$ do solo, onde não há mais sombreamento pelo estrato graminoso, alcançariam cerca de $70 \%$ de $\mathrm{A}^{\max }$ no campo sujo, e entre 50 e $60 \%$ de $A^{\max }$ no cerrado (Fig. 6).

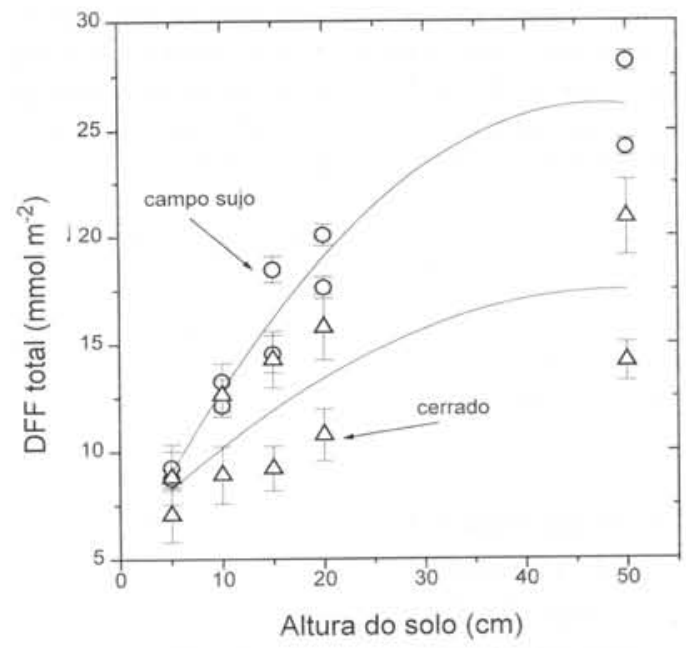

Figura 5. Valores integrados de densidade de fluxo de fótons na faixa fotossinteticamente ativa (DFF total) a diferentes alturas do solo no campo sujo e no cerrado da Fazenda Água Limpa, DF. 


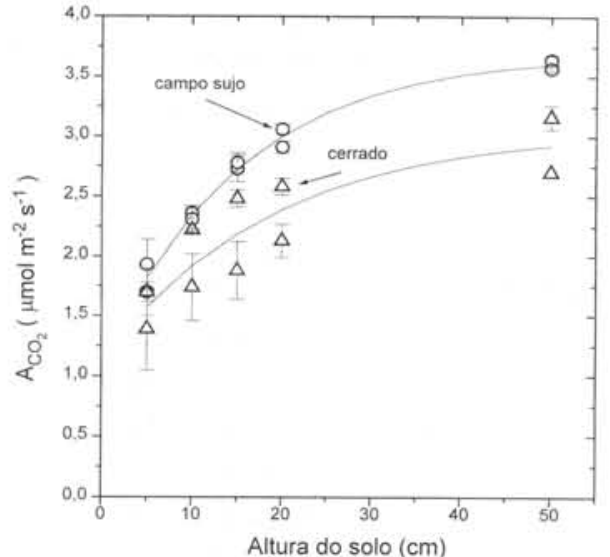

Figura 6. Taxa média estimada da assimilação líquida de $\mathrm{CO}_{2}\left(\mathrm{~A}_{\mathrm{CO} 2}\right)$ para folhas de D. miscolobium localizadas a diferentes alturas do solo. $\mathrm{A}_{\mathrm{CO}_{2}}$ foi estimada a partir da equação de Sassaki et al. (1997), utilizando-se as medidas instantâneas de DFF obtidas em dia típico do final da estação chuvosa (26/maio/1996) e do início da estação chuvosa (27/outubro/1996). Dados obtidos na Fazenda Água Limpa, DF e expressos em média \pm erro padrão $(n=6)$.

\section{Discussão}

A maior parte da mortalidade das mudas de D. miscolobium ocorreu nos primeiros meses após o transplante, durante a estação chuvosa. Padrão semelhante foi observado para mudas de $K$. coriaceae transplantadas em área de campo sujo na mesma região (Nardoto et al. 1998). Períodos secos (veranicos) são freqüentes durante a estação chuvosa na região CentroOeste e podem ser prejudiciais para a sobrevivência de mudas após o transplante, quando o sistema radicular ainda não está plenamente estabelecido. Hoffmann (1996) demonstrou que irrigação durante a estação chuvosa aumentou consideravelmente a sobrevivência de plântulas de Roupala montana Aubl. e Miconia albicans (Sw.) Triana, duas espécies lenhosas típicas do cerrado.

Fatores biológicos também influenciaram a sobrevivência de $D$. miscolobium. A infestação pelo fungo Phoma sp. provavelmente afetou a sobrevivência e a produtividade de $D$. miscolobium, especialmente na época chuvosa.
Algumas mudas morreram após serem fortemente infestadas pelo fungo. Apesar de não se ter quantificado os efeitos de patógenos, Marquis et al. (1999) relataram que a perda de área foliar pelo ataque de patógenos foi o triplo da causada pelos insetos, aumentando consideravelmente na época chuvosa. A herbivoria (percentagem estimada de área foliar removida para as folhas presentes na planta) atingiu seu pico na época seca. $\mathrm{O}$ pico de herbivoria registrado na estação seca também foi observado por Marquis et al. (2000) para várias espécies adultas do cerrado. Entretanto, os valores de herbivoria observados neste trabalho foram bem maiores do que os observados por aqueles autores ( $7 \%$ em média).

$\mathrm{Na}$ estação seca ocorreu redução significativa no crescimento de D. miscolobium e a perda da maioria das folhas pelas plantas, mostrando que a disponibilidade de água no solo afeta consideravelmente o seu desenvolvimento. Espécies lenhosas do cerrado apresentam restrição considerável da abertura estomática na época seca (Moraes \& Prado 1998; Franco 1998). Mudas de D. miscolobium, em condições de casa de vegetação, apresentaram valores de condutância estomática próximos a zero, a potenciais hídricos foliares de -1,5 MPa (Sassaki et al. 1997). Na mesma região do presente estudo, Nardoto et al. (1998) relataram que ao final da época seca, o potencial hídrico do solo em área de campo sujo, atingia valores inferiores a $-1,5 \mathrm{MPa}$ nos primeiros $60 \mathrm{~cm}$ do perfil do solo.

Variações na disponibilidade de luz em função da altura podem estar potencialmente limitando a aquisição de $\mathrm{CO}_{2}$ nas fases iniciais de desenvolvimento de D. miscolobium. Plantas de $5 \mathrm{~cm}$ de altura atingiriam, em média, apenas $32 \%$ de sua capacidade máxima de assimilação de $\mathrm{CO}_{2}$, devido ao sombreamento. À proporção que a planta crescesse, o sombreamento diminuiria, aumentando o potencial de assimilação de $\mathrm{CO}_{2}$. Aumento de altura da planta de 5 para $50 \mathrm{~cm}$ dobraria a assimilação estimada de $\mathrm{CO}_{2}$ (Fig. 6). Desta maneira, nas duas fitofisionomias, a luz é fator limitante importante na produtivi- 
dade dessa espécie nas fases iniciais de desenvolvimento. Como a cobertura herbácea apresentou altura máxima de $50 \mathrm{~cm}$, a obtenção dessa altura pela planta resultaria em aumento acentuado na disponibilidade de luz, na fotossíntese potencial e no desenvolvimento mais rápido da planta, especialmente no campo sujo. No cerrado, a presença de árvores resultou em atenuação da DFF mesmo a $50 \mathrm{~cm}$ de altura. Essa atenuação da DFF pela copa das árvores pode se tornar especialmente crítica em ambientes florestais como o cerradão. Nardoto et al. (1998) encontraram resultados semelhantes para plântulas de Kielmeyera coriacea em uma formação de campo sujo, sugerindo que a disponibilidade de luz também estaria limitando a capacidade de assimilação de $\mathrm{CO}_{2}$ dessa espécie nos primeiros anos de vida.

No campo sujo, a queimada acidental de 1994 não afetou a sobrevivência, enquanto as mudas transplantadas no cerrado sofreram mortalidade acentuada após a passagem do fogo. Os danos causados pelo fogo na vegetação são função da intensidade e da duração da frente de fogo (Wright \& Bailey 1982). Devido ao predomínio de vegetação herbácea, a passagem da frente de fogo foi provavelmente mais rápida no campo sujo. No cerrado sensu stricto, a estrutura da vegetaçãoé mais complexa, com maior acúmulo de material lenhoso. Silva (1996) relatou que a mortalidade em plantas lenhosas do cerrado diminui com o aumento de tamanho do indivíduo, tendo indivíduos adultos (diâmetro superior a $5 \mathrm{~cm}$ a $30 \mathrm{~cm}$ do nível do solo) de D. miscolobium apresentado mortalidade entre 3 e $6 \%$ após a passagem do fogo.

$\mathrm{O}$ fogo causou perda total da parte aérea e as plântulas sobreviventes rebrotaram a partir da base, levando a desenvolvimento acentuado da parte aérea nos primeiros meses após o fogo. Houve pico nas taxas de crescimento do caule e produção de folhas após o fogo, sugerindo que mesmo indivíduos jovens dessa espécie acumulam reservas nutricionais suficientes para sobreviver a perturbações como o fogo. Moreira
(1992), Sassaki \& Felippe (1992) e Sassaki et al. (1997) mostraram que maior proporção da biomassa total estava no sistema radicular, durante o desenvolvimento inicial de plântulas dessa espécie.

Os resultados obtidos indicam que $D$. miscolobium mostrou-se capaz de colonizar a matriz graminosa, apresentando inclusive sobrevivência maior neste tipo de ambiente mais aberto (campo sujo). O desenvolvimento da parte aérea nos primeiros anos de vida foi lento, com tendência a maior acumulação de biomassa no campo sujo. Além do efeito de sombreamento pelo dossel graminoso, estudos são necessários para analisar seus padrões de alocação de biomassa para estruturas subterrâneas e determinar o grau de interferência do sistema radicular das gramíneas no desenvolvimento e crescimento lento desta espécie durante seu estabelecimento nas formações savânicas do Planalto Central.

\section{Agradecimentos}

Este trabalho foi financiado pela International Foundation for Science (Suécia), pelo CNPq e o PRONEX. Os dados de precipitação foram gentilmente cedidos pela Reserva Ecológica do IBGE, Brasília, DF. Os autores são gratos à Fazenda Experimental da Universidade de Brasília pelo apoio logístico durante a realização dessa pesquisa. Inésio A. M. Correa montou o sistema de medição de luz.

\section{Referências bibliográficas}

Batmanian, G. J. \& Haridasan, M. 1985. Primary production and accumulation of nutrients by the ground layer community of cerrado vegetation of central Brazil. Plant and Soil 88: 437-440.

Fowler, H. G. \& Duarte, L. C. 1991. Herbivore pressure in a Brazilian cerrado. Naturalia 16: 99-102.

Franco, A. C. 1998. Seasonal patterns of gas exchange, water relations and growth of Roupala montana, an evergreen savanna species. Plant Ecology 136: 69-76.

Franco, A. C.; Nardoto, G. B. \& Souza, M. P. 1996. Patterns of soil water potential and seedling survival in the cerrados of central Brazil. Pp.277-280. In: Anais do VIII Simpósio sobre o Cerrado. Brasília 1996. EMBRAPA/CPAC, Brasília. 
Handro, W. 1969. Contribuição ao estudo da unidade de dispersão e da plântula de Andira humilis Mart. Ex Benth. (Leguminosae-Lotoideae). Boletim da Faculdade de Filosofia Ciências e Letras da Universidade de São Paulo 347, Botânica 27: 1-189.

Hoffmann, W. A. 1996. The effects of fire and cover on seedling establishment in a neotropical savanna. Journal of Ecology 84: 383-393.

Laboriau, L. G.; Válio, I. F. M.; Salgado-Laboriau, M. L. \& Handro, W. 1963. Nota sôbre a germinação de sementes de plantas de cerrados em condições naturais. Revista Brasileira de Biologia 23: 227-237.

Marquis, R. J.; Diniz, I. R. \& Morais, H. C. 2000. Patterns and correlates of interspecific variation in foliar insect herbivory and pathogen attack in Brazilian cerrado. Journal of Tropical Ecology, (no prelo)

Medina, E. \& Silva, J. F. 1990. Savannas of northern South America: a steady-state regulated by water-fire interactions on a background of low nutrient availability. Journal of Biogeography 17: 403-413.

Moraes, J. A. P. V. \& Prado, C. H. B. A. 1998. Photosynthesis and water relations in cerrado vegetation. Pp. 45-63. In: F. R. Scarano \& A. C. Franco (Eds.), Ecophysiological strategies of xerophytic and amphibious plants in the neotropics. Series Oecologia Brasiliensis vol 4. PPGE-UFRJ, Rio de Janeiro.

Moreira, A.G. 1992. Fire protection and vegetation dynamics in the Brazilian cerrado. Tese de Doutorado. Havard University, Massachusetts.
Nardoto, G. B.; Souza, M. P. \& Franco, A. C. 1998. Estabelecimento e padrões sazonais de produtividade de Kielmeyera coriacea (Spr.) Mart. nos cerrados do Planalto Central: efeitos do estresse hídrico e sombreamento. Revista Brasileira de Botânica. 21: 313-319.

Oliveira, P. E. \& Silva, J. C. S. 1993. Reproductive biology of two species of Kielmeyera (Guttiferae) in the cerrados of Central Brazil. Journal of Tropical Ecology 9: 67-79.

Sassaki, R. M. \& Felippe, G. M. 1992. Remoção dos cotilédones e desenvolvimento inicial de Dalbergia miscolobium. Revista Brasileira de Botânica 15: 516.

Sassaki, R. M.; Machado, E. C.; Lagôa, A. M. M. A. \& Felippe, G. M. 1997. Effect of water deficiency on photosynthesis of Dalbergia miscolobium Benth., a cerrado tree species. Revista Brasileira de Fisiologia Vegetal 9: 83-87.

Sato, M. N. 1996. Mortalidade de plantas lenhosas do cerrado submetidas a diferentes regimes de queima. Dissertação de Mestrado. Universidade de Brasília, Brasília.

Wright, S. J. \& Bailey, A. W. 1982. Fire Ecology. John Wiley \& Sons, New York. 